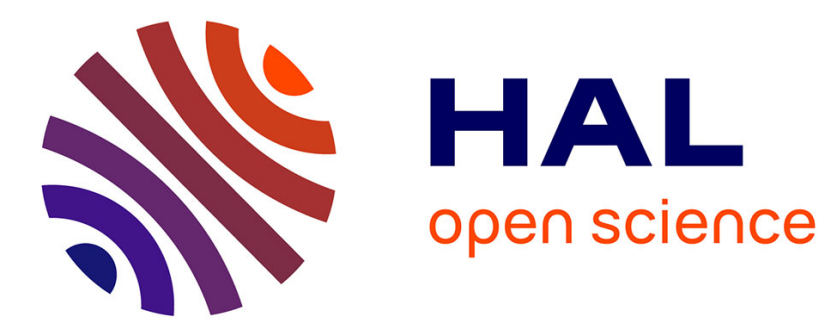

\title{
Maximizing amount of transferred traffic for battery powered mobiles
}

\author{
Eitan Altman, Mandar Datar, Ghilas Ferrat
}

\section{To cite this version:}

Eitan Altman, Mandar Datar, Ghilas Ferrat. Maximizing amount of transferred traffic for battery powered mobiles. Netgcoop 2020 - International Conference on NETwork Games, Control and Optimisation, Sep 2021, Cargese, France. 10.1007/978-3-030-87473-5_8 . hal-02931313

\section{HAL Id: hal-02931313 \\ https://hal.inria.fr/hal-02931313}

Submitted on 6 Sep 2020

HAL is a multi-disciplinary open access archive for the deposit and dissemination of scientific research documents, whether they are published or not. The documents may come from teaching and research institutions in France or abroad, or from public or private research centers.
L'archive ouverte pluridisciplinaire HAL, est destinée au dépôt et à la diffusion de documents scientifiques de niveau recherche, publiés ou non, émanant des établissements d'enseignement et de recherche français ou étrangers, des laboratoires publics ou privés. 


\title{
Maximizing amount of transferred traffic for battery powered mobiles
}

\author{
Eitan Altman ${ }^{1,2}$, Mandar Datar ${ }^{1,2}$, and Ghilas Ferrat ${ }^{1,2}$ \\ 1 INRIA Sophia Antipolis -e \\ 2 CERI/LIA, University of Avignon, Avignon, France;
}

\begin{abstract}
There is a fast growing demand for mobile telephones. These rely on batteries to provide the power needed for transmission and for reception (up and downlink communications). Considering uplink, we analyse how the characteristics of the battery affect the amount of information that one can draw out from the terminal. We focus in particular on the impact of the charge in the battery on the internal resistance which grows as the battery depletes.
\end{abstract}

\section{Introduction}

In the design of power control algorithms, often one takes into account the level of depletion of the battery. When the battery is almost empty, a power saving mode is often applied. While this allows to prolongue the battery life, it is of interest to compare the benefits of this algorithm with one obtained from mathematical formulation of the problem as an optimisation one. In this paper we propose such a model that takes into account dynamic behavior of the battery and the fact that the internal battery resistance changes as a function of the battery's charge. Indeed, it is stated in that

"Li-ion has higher resistance at full charge and at end of discharge with a big flat low resistance area in the middle. Alkaline, carbon-zinc and most primary batteries have a relatively high internal resistance, and this limits their use to low-current applications such as flashlights, remote controls, portable entertainment devices and kitchen clocks. As these batteries deplete, the resistance increases further". We shall use the latter behavior in our modeling.

Our goal is to combine the dynamic behavior of the battery as function of its charge with capacity limits on transmission throughput from information theory to obtain limits on the amount of data that can be transmitted by mobiles that are powered with a battery.

\section{Model}

We assume that a fully charged battery has $F$ Coulombs. The figures in [1] suggest that the battery internal resistance $R$ is linear decreasing in the battery's charge $c$ and is thus given by $R(t)=R_{0}-\rho c(t)$ for some constants $\rho$ and $R_{0}$. The current $i$ satisfies $\frac{d R(t)}{d t}=\rho i(t)$ since $d c / d t=-i$. 
We model the battery by a source of $V$ volts with the internal resistance of $R$. Another resitor $r$ is then connected in series to the two other elements and it represents the terminal equipment (TE). We have $i=\frac{V}{R+r}$ Thus $\frac{d R(t)}{d t}=\frac{\rho V}{R(t)+r}$

\section{Analysis and Results}

The solution of this differential equation is

$$
R(t)=\sqrt{2 \rho t V+\left(r+R_{0}\right)^{2}}-r
$$

for some constants $\rho$ and $R_{0}$. We could easily verify that $R(0)=R_{0}$ and that $\frac{d R(t)}{t}=\frac{\rho V}{R(t)+r}$. And so, $i(t)=\frac{V}{\sqrt{2 \rho t V+\left(r+R_{0}\right)^{2}}}$.

We can then compute the time $T(x)$ the battery takes to discharge from $F$ to $x$ as the solution of $F-x=\int_{0}^{T(x)} i(t) d t$. We finally get the closed form expression of $T(x)=\frac{1}{2 V}(F-x)\left[2\left(r+R_{0}\right)+\rho(F-x)\right]$. The power spent at the $\mathrm{TE}$ is given by

$$
P(t)=r i(t)^{2}=\frac{r V^{2}}{\left(r+R_{0}\right)^{2}+2 \rho V t}
$$

Assume that all this power is transmitted and that the channel gain to the base station is $h$. Then assuming a single user and that the throughput $\Theta$ is given by Shannon capacity [2], we have for some constants $W$ and $N$,

$$
\Theta(t)=W \ln \left(1+\frac{P(t) h}{N}\right)=W \ln \left(1+\frac{r h V^{2}}{N\left(\left(r+R_{0}\right)^{2}+2 \rho V t\right)}\right)
$$

and the total amount of data that can be transmitted is $\int_{0}^{T(0)} \Theta d t$, denoted TA.

In practice a terminal has to use some constant power $\Delta$ for its electronic circuit which reduces the amount of data transferred.

$$
\begin{gathered}
T A(0)=\int_{0}^{T(0)} \Theta(t) d t-\Delta T(0)= \\
\int_{0}^{T(0)} W \ln \left(1+\frac{r h V^{2}}{N\left(\left(r+R_{0}\right)^{2}+2 \rho V t\right)}\right) d t-\Delta T(0) \\
=W\left[\int_{0}^{T(0)} \ln \left[N\left(r+R_{0}\right)^{2}+2 N \rho V t+r h V^{2}\right] d t-\int_{0}^{T(0)} \ln \left[N\left(r+R_{0}\right)^{2}+2 N \rho V t\right] d t\right]-\Delta T(0)
\end{gathered}
$$

Using

$$
\frac{d}{d x} \frac{1}{a}((a x+b) \ln (a x+b)-(a x+b))=\ln (a x+b)
$$

and computing the TA, we get that

$$
T A(0)=W\left(\frac{1}{2 N \rho V} N\left(r+R_{0}\right)^{2}\right.
$$




$$
\begin{gathered}
\ln \left(1-\frac{2 N \rho V T(0) r h V^{2}}{\left(r h V^{2}+N\left(r+R_{0}\right)^{2}\right)\left(N\left(r+R_{0}\right)^{2}+2 N \rho V T(0)\right)}\right) \\
\quad+\frac{1}{2 N \rho V} r h V^{2} \ln \left(1+\frac{2 N \rho V T(0)}{r h V^{2}+N\left(r+R_{0}\right)^{2}}\right) \\
\left.+T(0) \ln \left(1+\frac{r h V^{2}}{2 N \rho T(0)+N\left(r+R_{0}\right)^{2}}\right)\right)-\Delta T(0)
\end{gathered}
$$

\section{Maximization of the average throughput}

Previously we had a closed form expression of the time $T(x)$ that the battery takes to discharge from an initial charge $F$ to a $x$ level.

$$
\begin{gathered}
T(x)=\frac{(F-x)\left[2\left(r+R_{0}\right)+\rho(F-x)\right]}{2 V} \\
T A(x)=\int_{0}^{T(x)}\left(W \ln \left(1+\frac{r h V^{2}}{N\left(r+R_{0}\right)^{2}+2 \rho N V t}\right)-\Delta\right) d t
\end{gathered}
$$

We also had a closed form expression of the total amount of data transmitted until we reach a $x$ level of battery, $T A(x)$. Here the objective is to maximize the average throughput before charging the device, denoted $A P(x)$. Mathematically, the program can be written as

$$
\max _{x \in[0 ; F]} A P(x)=\frac{T A(x)-T C(x)}{T(x)}
$$

Let $\mathcal{L}(x, \lambda)=\frac{T A(x)-T C(x)}{T(x)}+\lambda(F-x)$ be the Lagrangian of the program. Solving it leads to

$$
\left\{\begin{array}{l}
\frac{\partial}{\partial x} \mathcal{L}(x, \lambda)=0 \\
\frac{\partial}{\partial \lambda} \mathcal{L}(x, \lambda)=0
\end{array}\right.
$$

We consider a case in which the total cost of charging the device is the same whether the battery is empty or almost full, denoted $T C(x)=\gamma$.

$$
\Longleftrightarrow\left\{\begin{array}{l}
\frac{T^{\prime}(x)\left(\Theta\left(T(x)-\Delta-T C^{\prime}(x)\right) T(x)-(T A(x)-T C(x))\right)}{T(x)^{2}}-\lambda=0 \\
F-x=0
\end{array}\right.
$$

Considering the case of a border solution where $\lambda>0$, we have $x^{*}=F$. Meaning that an agent charges the device, every time his battery full. In the case of an internal solution, where $\lambda=0$, the first equation leads to either $T^{\prime}(x)=0$ or $\Theta(T(x)) T(x)-\Delta T(x)-T A(x)+\gamma=0$. The corresponding solution to $T^{\prime}(x)=0$ is $x=F+\frac{r+R_{0}}{\rho}>F$ therefore impossible considering the program. Using the software Maple(Maplesoft $)$ for the second equation, the time necessary to reach an optimal level of battery before charging the device $T\left(x^{*}\right)$ given by,

$$
T\left(x^{*}\right)=\frac{e^{\text {Root }}}{2 \rho N V}
$$


Where Root is the solution of the following equation in terms of $\mathrm{z}$,

$$
\begin{aligned}
& 2 W\left(N\left(r+R_{0}\right)^{2}+2 \rho N V\right) \ln \left(r h V^{2}+N\left(r+R_{0}\right)^{2}\right) \\
& +W\left(e^{z}-4 \rho N V\right) \ln \left(r h V^{2}+N\left(r+R_{0}\right)^{2}+e^{z}\right) \\
& -2 W\left(N\left(r+R_{0}\right)^{2}+e^{z}\right) \ln \left(r h V^{2}+e^{z}\right)+2 W N\left(r+R_{0}\right)^{2} z \\
& -W e^{z} \ln \left(N\left(r+R_{0}\right)^{2}+e^{z}\right)+2(W z-\Delta) e^{z} \\
& -2 W N\left(r+R_{0}\right)^{2} \ln \left(N\left(r+R_{0}\right)^{2}\right)+2 \gamma \rho N V=0
\end{aligned}
$$

In order to compute the internal solution $x^{*}$, the inverse function of $T(x)$ must be computed, and finally, the optimal level of battery is given by,

$$
x^{*}=\frac{\rho F+r+R_{0}}{\rho}-\frac{\sqrt{e^{\text {Root }}+N\left(r+R_{0}\right)^{2}}}{\rho \sqrt{N}}
$$

This solution has sense since it belongs to $[0 ; F]$ and that the agent charges his device only once his battery is at a lower level than the full level.

\section{Conclusions}

We have derived closed form solutions to the amount of information that a battery powered terminal can deliver. The next thing to do is to add a cost function that would penalize using the battery as a function of its charge so as to penalize operating it when the internal capacity of the battery is large. Indeed, as $R$ increases, the efficiency of the battery decreases: most of its remaining power is spent on heating the battery as it is spent on $R$. Assuming that recharging the battery is costly, we have optimized over the level $x$ of remaining charge in the battery at which the charging would begin so as to minimize the cost per cycle of depletion and recharging. We also plan to investigate interference and competition that may arise when more that one terminal is connected with a common base station. This is the objective of our future work.

\section{References}

1. https://batteryuniversity.com/learn/article/

2. https://en.wikipedia.org/wiki/Shannon 